patients (20\%), more than $50 \%$ of recorded spasms were asymmetric or asynchronous. This group of patients showed the most frequent structural and functional brain abnormalities involving the contralateral central region detected by EEG, MRI, PET, and neurological examination. Partial seizures with lateralized motor behavior occurred in 50\% of this group compared to only $9 \%$ of patients showing asymmetry-asynchrony in less than one third of spasms. Partial seizures were associated with clusters of infantile spasms in $35 \%$ of the children in the study. (Gaily EK et al. Asymmetric and asynchronous infantile spasms. Epilepsia Aug/Sept 1995;36:873-882). (Reprints: Dr EK Gaily, Department of Child Neurology, University of Helsinki, Children's Castle Hospital, Lastenlinnantie 2, SF-00250 Helsinki, Finland).

COMMENT. The authors suggest that this combination of asymmetric and/or asynchronous infantile spasms, partial motor seizures involving the same side of the body, and contralateral central region pathology may represent a previously undescribed and unique subset of symptomatic age-specific localization-related infantile epilepsy. The findings support the hypothesis that infantile spasms are generated by the cerebral cortex and the primary sensorimotor cortex is involved in asymmetric and asynchronous spasms.

\title{
PREVALENCE OF EPILEPSY IN 10-YEAR-OLDS
}

The prevalence of epilepsy and seizure types among 10-year-old children in metropolitan Atlanta were ascertained from EEG laboratories and other sources and reported from the Centers for Public Health Research, Battelle; Division of Birth Defects, Center for Disease Control and Prevention; and Children's Epilepsy Center, Scottish Rite Children's Medical Center, Atlanta, GA. For the 538 patients identified, the lifetime prevalence of childhood epilepsy was 6 per 1000 10-year-old children. Boys outnumbered girls, especially among black children. Partial and secondarily generalized seizures accounted for $58 \%$ and generalized seizures for $35 \%$. Coexisting developmental disabilities affected 35\%. Mental retardation occurred in $30 \%$ of whom two thirds were severely retarded, cerebral palsy in $18 \%$, visual impairment in 5\%, and hearing impairment in 2\%. Forty percent had a first seizure before 2 years of age and $55 \%$ before 4 years. (Murphy CC et al. Prevalence of epilepsy and epileptic seizures in 10-year-old children: Results from the Metropolitan Atlanta developmental disabilities study. Epilepsia Aug/Sept 1995;36:866-872). (Reprints: Dr CC Murphy, Centers for Disease Control and Prevention, Division of Birth Defects and Developmental Disabilities, 4770 Buford Highway, Mailstop F-15, Atlanta, GA 30341).

COMMENT. A higher rate for epilepsy of 9.8 per 1000 children $<15$ years found by Hauser WA, (1994) in Rochester, MN was thought to reflect a more complete case ascertainment in a well-defined stable population. Children with milder forms of epilepsy and those no longer under medical care may have been missed in the Atlanta study. Prevalence rates for active epilepsy may be lower than rates for lifetime prevalence.

\section{IDIOPATHIC GENERALIZED EPILEPSY SYNDROMES}

The clinical features of 101 patients with idiopathic generalized epilepsy beginning in adolescence were studied by standardized interview at the Department of Neurology, Austin Hospital, and the Department of Medicine, 